\title{
Evaluation of the GPR (1.2 GHz) technique in the characterization of masonry shells of the Theatro Municipal do Rio de Janeiro
}

\section{Avaliação da técnica de GPR $(1,2 \mathrm{GHz})$ na caracterização das cascas em alvenaria do Theatro Municipal do Rio de Janeiro}

D. C. B. CINTRA a

daniellicbc@gmail.com

https://orcid.org/0000-0003-4246-894X

P. M. B. MANHÃES a paola manhaes@yahoo.com.b https://orcid org/0000-0001-7539-2879

F. M. C. P FERNANDES : https://orcid.org/0000-0002-7575-411X

D. M. ROEHL a

droehl@puc-rio.br https://orcid.org/0000-0003-4644-120X

J. T. ARARUNA JÚNIOR a araruna@puc-rio.br https://orcid.org/0000-0002-4066-1765

E. S. SÁNCHEZ FILHO ${ }^{\circ}$ emilsanchez@uol.com.br

\section{Abstract}

The geometric characterization and evaluation of structural integrity are challenges for the preservation of historical buildings. The challenges are associated to the lack of constructive records, material diversity, access and contact restrictions, and sample extraction. Non-destructive tests are indicated in these cases. The objective of this paper is to evaluate the Ground Penetrating Radar (GPR) technique with $1.2 \mathrm{GHz}$ antenna in the study of the determination of material thickness and discontinuities in the masonry shells of the Theatro Municipal do Rio de Janeiro, a heritage built in early 20 th century, with high historical and cultural value. With paintings by renowned artists on their intrados, the domes and vault of brick masonry were at risk of collapse in the 1970s due to differential settlements in the supports and moisture, compromising their paintings. A strengthening intervention was carried out in 1976. Considering the masonry of bricks the main component, the electromagnetic wave propagation velocity was determined as $0,15 \mathrm{~m} / \mathrm{ns}$ in one of the support walls, allowing to estimate the thicknesses of the elements ranging between 20 and $31 \mathrm{~cm}$. Materials incorporated into the structure were identified: reinforcement, metal inserts and bricks. However, the frequency of the antenna did not allow the detection of damages. The application of the GPR to the characterization of materials and investigation of the integrity of the domes of the Theatro Municipal highlights the potential of this technology to study heritage and other constructions.

Keywords: Ground Penetrating Radar (GPR), dome, vault, historical buildings, Theatro Municipal do Rio de Janeiro.

\section{Resumo}

A caracterização geométrica e avaliação da integridade estrutural são desafios para a preservação de edifícios históricos. Os desafios estão associados à escassez de registros construtivos, diversidade de materiais, restrições de acesso, contato e extração de amostras. Nesses casos são indicados ensaios não destrutivos. Este trabalho tem como objetivo avaliar a técnica do Ground Penetrating Radar (GPR), com antena de 1,2 GHz, na determinação de espessuras e descontinuidades nas cascas em alvenaria do Theatro Municipal do Rio de Janeiro, patrimônio construído no início do século XX, de elevado valor histórico e cultural. Com pinturas de artistas renomados em seu intradorso, as cúpulas e abóbada em alvenaria de tijolos estiveram risco de colapso na década de 1970 devido a recalques diferenciais e umidade, comprometendo as pinturas. O reforço da estrutura com concreto projetado foi realizado em 1976. Considerando a alvenaria de tijolos o principal componente, a velocidade de propagação de onda eletromagnética foi determinada em $0,15 \mathrm{~m} / \mathrm{ns}$ em uma das paredes de apoio, permitindo estimar a variação entre 20 e $31 \mathrm{~cm}$ nas espessuras dos elementos estudados. Foram mapeados outros materiais incorporados à estrutura como armadura, chumbadores e tijolos, porém a frequência da antena não permitiu a detecção de danos. A aplicação do GPR para a investigação de integridade e caracterização de materiais das cúpulas do Theatro Municipal mostra o potencial dessa técnica para estudos de patrimônio histórico e de outras construções.

Palavras-chave: Ground Penetrating Radar (GPR), cúpula, abóbada, construções históricas, Theatro Municipal do Rio de Janeiro. 


\section{Introduction}

According to the International Council of Monuments and Sites, the preservation of heritage buildings has a multidisciplinary character and a structural analysis can be useful for estimating the conservation status of the building, as well as for assessing the efficiency of intervention techniques [1]. In this context, the characterization and evaluation of the integrity of the structural elements become fundamental, although it is a generally complex task due to the lack of constructive records and interventions, as well as restrictions on access, contact and especially sample extraction.

Non-destructive tests are investigative resources that do not cause permanent damage to the tested element, causing no loss of its resistant capacity. These tests are great value for the study of historical heritage, which cannot be subjected to changes that compromise its authenticity. Without testimonials and without knowing the material properties and element dimensions, the accuracy of the information obtained in non-destructive testing is considerably compromised. However, according to Balayssac et al. (2012) and Milovanovic and Pecur (2016) [2,3]but several kinds of indicators representative of the concrete condition need to be evaluated. Combining NDT methods is currently considered as one of the most appropriate ways to improve the quality of the diagnosis of concrete structures. This paper describes a French project named SENSO (Strategy of non-destructive evaluation for the monitoring of concrete structures, the combination of various tests, care in their execution and knowledge of the factors that influence results can facilitate data interpretation and validate the estimation of desired information.

The Ground Penetrating Radar (GPR) is considered by Benedetto and Benedetto (2014) as one of the most efficient and promising remote sensing technologies available for civil engineering applications [4]. Because it is non-invasive, it is a research technique recommended by many researchers for inspection and diagnostic work on foundations [5,6], concrete paving [7-9], concrete bridge decks [10-14]. GPR is also used in ancient structures, especially stone and brick masonry, to map internal characteristics of the structure and to evaluate the homogeneity of the constituent material [15-19]. Under appropriate test conditions, GPR can provide realistic information on the shape and position of targets within building elements.

The high-frequency antennas ( $\geq 1000 \mathrm{MHz}$ ) used for GPR data acquisition allow the verification of structure geometry, the detection of reinforcement, prestressing bars, metallic elements in general, the presence of delamination and humidity [6], as well as indicating areas affected by corrosion [13]. In masonry, the combination of two-dimensional GPR reflection techniques with three-dimensional techniques and other non-destructive testing methods enables the detection of voids, thickness of walls, vaults, domes, arches and fillings of bridge and shells, metal elements and damage [6].

One of the major references of Brazilian heritage, the Theatro Municipal do Rio de Janeiro (TMRJ) (Figure 1), plays an important role for Rio de Janeiro and national culture, being directed by Foundation of Theatro Municipal do Estado do Rio de Janeiro. It was built between 1905 and 1909, simultaneously with other monumental buildings in the surrounding area, such as the Biblioteca Nacional, Museu Nacional de Belas Artes, former Caixa de Amortização, which together are listed by the Instituto de Patrimônio Histórico e Artístico Nacional (IPHAN) as an architectural ensemble of Avenida Central since 1973 [20]. In addition to these buildings are also the Clube Naval and the Palácio Monroe (demolished in 1976), built at the same time, in an effort by Mayor Pereira Passos to build the Avenida Central for the modernization of the city, which was the capital of the country. Cintra et al. describe the Theatro building construction system and the history of the structural interventions over the years [21].

With paintings by renowned artists such as Eliseu Visconti and Henrique Bernardelli on the intrados, the side domes and vault built in brick

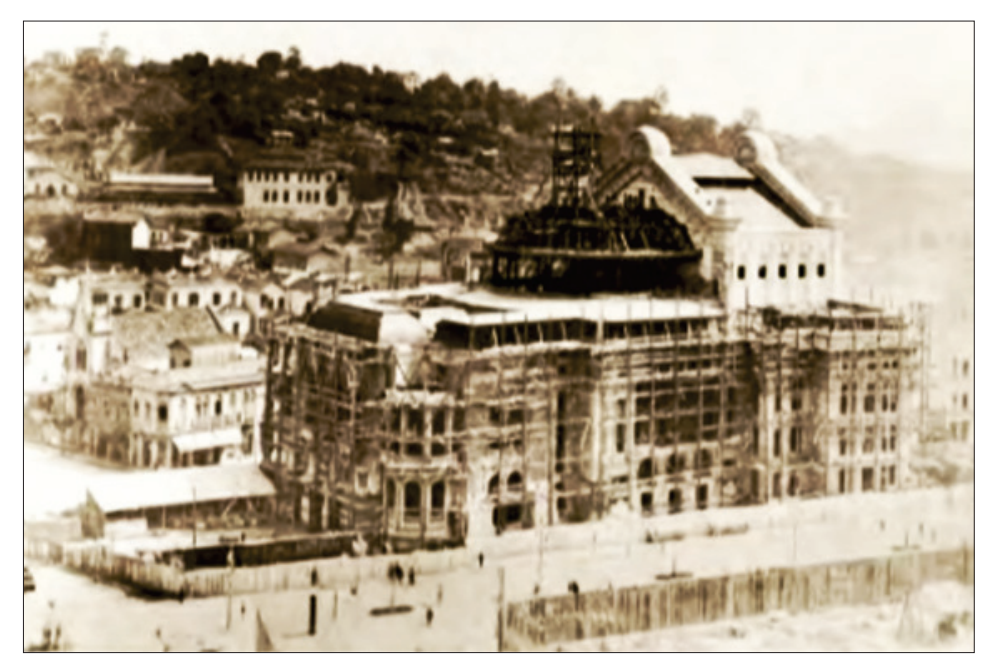

(a)

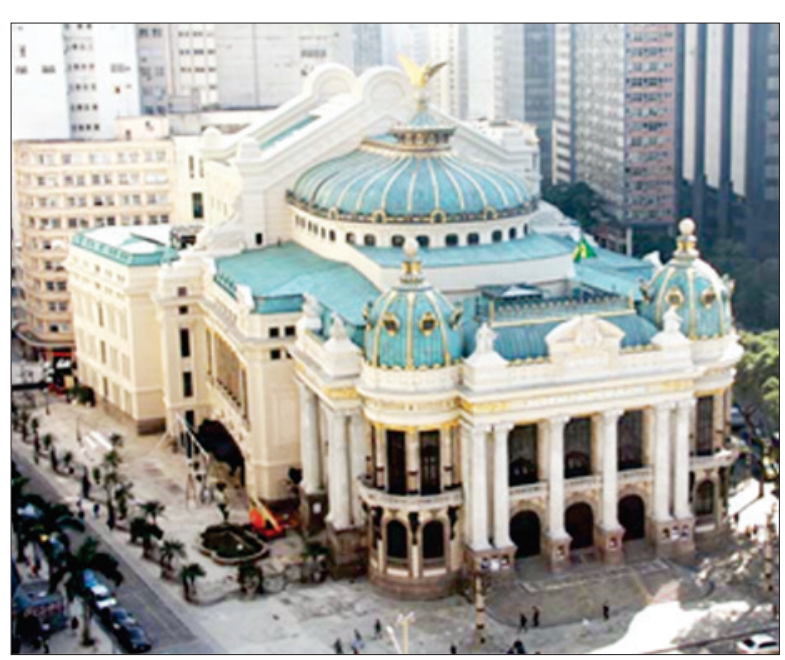

(b)

\section{Figure 1}

(a) Augusto Malta photo of roof construction, 1906; (b) current façade

Source: O Theatro Municipal - História. In: http://www.theatromunicipal.rj.gov.br/sobre/historia/, accessed: 10/12/2016 


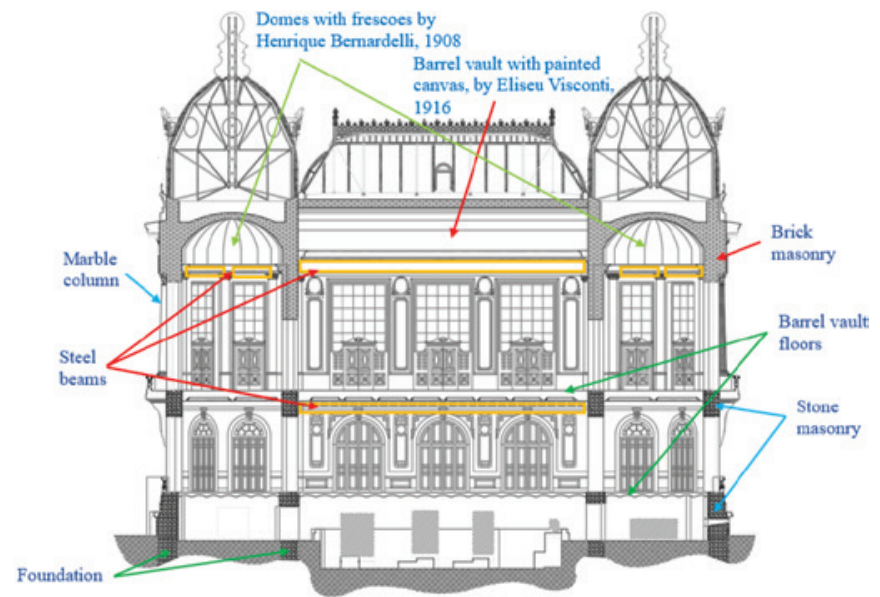

Figure 2

Cross-section of the noble area of the Theatro Municipal do Rio de Janeiro

Source: Adapted from architectural drawing [29]

masonry of the TMRJ (Figure 2) are objects of study of preventive structural monitoring in PUC-Rio, in a campaign of non-destructive tests to characterize the structure, relied on the group of historical constructions of the University of Minho to analyse the results of the GPR test.

This work aims at evaluating the GPR technique with $1.2 \mathrm{GHz}$ antenna for the determination of thickness and discontinuities of the masonry shells of the TMRJ. The GPR technique was applied to estimate the total thickness of the shells, their constituent layers and to compare bricks dimensions with data from other tests. In addition, the GPR can help detect any materials incorporated into the elements and damage. The information obtained in the experimental program was used in a subsequent numerical modelling step for nonlinear analysis of the structure by the finite element method to investigate possible causes of damage and to evaluate the efficiency of intervention measures already performed. Relevant concepts of the GPR technique are presented. The comprehension of these techniques is fundamental for proper application in typical masonry of historical buildings. The work proposes a survey methodology and data analysis for the historical structure, as well as conclusions and suggestions for future works.

\section{Theoretical and experimental aspects of GPR tests}

GPR is a non-destructive technique based on the propagation of radio frequency electromagnetic waves. It finds application in the assessment of the integrity of wood and concrete structures, tunnels, bridges and road pavements, as well as in the inspection of historical structures. The technique uses devices capable of recording the transmission and reception flux of electromagnetic waves that propagate in the medium and reflect when they strike elements with contrasting properties. This makes it possible to identify discontinuities, profile layers of different materials below a surface, or even to classify the geometry of a hidden target as flat, long, thin, spherical or cubic under favourable test conditions [25].

\subsection{Physical principles}

The technique is based on the fact that the velocity and amplitude of electromagnetic waves vary significantly between materials. Therefore, a signal transmitted in two different materials, travelling the same distance, will arrive at different times. The speed and the way waves propagate, reflect and attenuate in the medium depend on the dielectric properties of materials related to the ability to store electrical charge in the presence of an electric field. Table 1 presents typical values of relative dielectric constant and static electrical conductivity for an antenna frequency of $100 \mathrm{MHz}$, as well as wave speed and attenuation for common materials. The general expression for the propagation velocity of a wave pulse in homogeneous and isotropic materials is given by Equation 1 [22,25]:

$v_{r}=\frac{\mathbf{c}}{\sqrt{\varepsilon_{r}}}$

Table 1

Electromagnetic properties of some materials

\begin{tabular}{|c|c|c|c|c|}
\hline Material & $\begin{array}{c}\text { Relative dielectric } \\
\text { constant } \\
\left(\varepsilon_{\mathrm{r}}\right)\end{array}$ & $\begin{array}{l}\text { Electric conductivity }(\sigma) \\
\mathrm{mS} / \mathrm{m}\end{array}$ & $\begin{array}{l}\text { Wave speed }(\varpi) \\
\mathrm{m} / \mathrm{ns}\end{array}$ & $\begin{array}{l}\text { Wave attenuation }(\alpha) \\
\mathrm{dB} / \mathrm{m}\end{array}$ \\
\hline Air & 1 & 0 & 0.300 & 0 \\
\hline Water & $78\left(25^{\circ} \mathrm{C}\right)$ to 88 & 0.1 to 10 & 0.032 to 0.034 & 0.01 \\
\hline Sea water & 81 to 88 & 4000 & 0.032 to 0.033 & 103 \\
\hline Dry sand & 3 to 6 & $10-4$ to 1 & 0.122 to 0.173 & 0.01 to 1 \\
\hline Wet sand & 10 to 30 & 0.1 to 10 & 0.055 to 0.095 & 0.05 to 5 \\
\hline Dry clay & 2 to 20 & 1 to 100 & 0.067 to 0.212 & 10 to 50 \\
\hline Wet clay & 15 to 40 & 100 to 1000 & 0.047 to 0.077 & 20 to 100 \\
\hline Dry granite & 5 to 8 & $10-3$ to $10-5$ & 0.106 to 0.134 & 0.5 to 3 \\
\hline Wet granite & 5 to 15 & 1 to 10 & 0.077 to 0.134 & 2 to 5 \\
\hline Dry concrete & 4 to 10 & 1 to 10 & 0.095 to 0.150 & 2 to 12 \\
\hline Wet concrete & 10 to 20 & 10 to 100 & 0.067 to 0.095 & 10 to 25 \\
\hline
\end{tabular}

Source: Adapted from Annan, Daniels and Cassidy [22, 23, 25] 


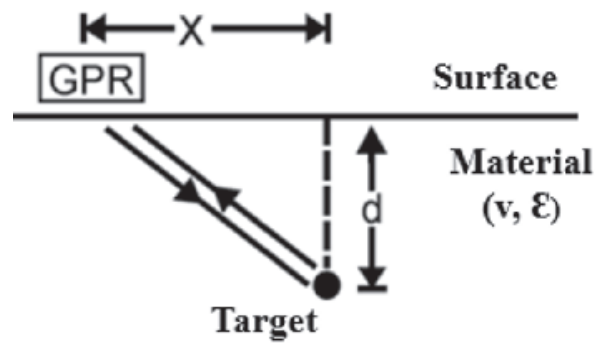

Figure 3

Relationship between GPR position ( $\mathrm{x}$ ), target depth (d) during travel time ( $\mathrm{T}$ )

Source: Adapted from Annan [22]

where,

$v_{r}$ - relative velocity of propagation of electromagnetic wave pulse in a solid medium;

$c$ - velocity of the electromagnetic wave in the air, equal to light $0,3 \mathrm{~m} / \mathrm{ns}$;

$\varepsilon_{\mathrm{r}}-$ relative dielectric constant of the material.

The presence of moisture in the materials increases the relative dielectric constant, which decreases the propagation velocity of electromagnetic waves, as indicates in Table 1. Soluble salts or saline water present in materials, very common in marine environments, increase the electrical conductivity and the wave attenuation, decreasing the penetration depth of the electromagnetic signal, with significant loss of propagation energy. In such cases, GPR research may be compromised [22].

According to Alsharahi et al. (2016) [24], as the wave propagates in a medium, the contrast of the dielectric constant between the materials causes the reflection of the electromagnetic waves at the interface, while the electrical conductivity attenuates the propagation of the waves. The incident energy is partially reflected and partially transmitted, depending on the contrast between the relative dielectric constants of the adjacent materials. Metallic materials tend to reflect all incident electromagnetic energy.

The time that the signal takes from its transmission through reflec-

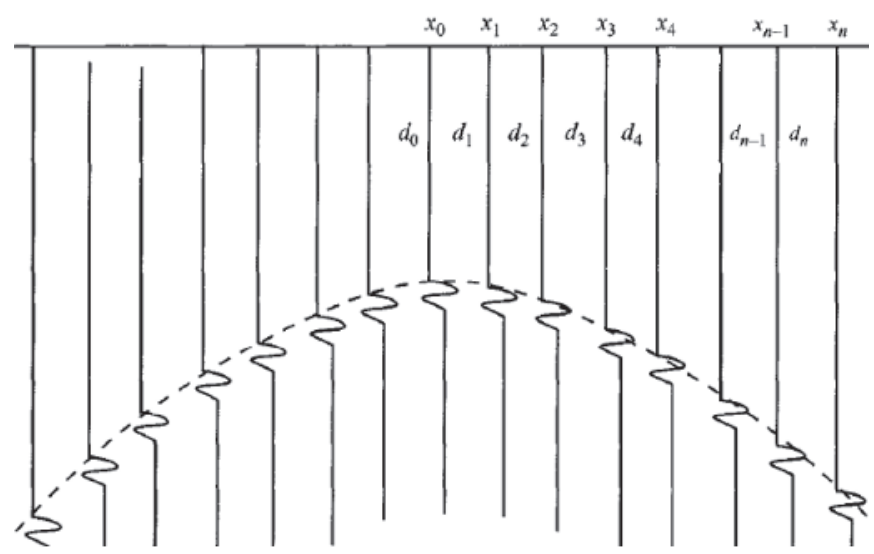

Figure 4

Hyperbolic distribution function

Source: Daniels [25] tion on a target to its reception is called the round-trip time and depends on the wave frequency and properties of the propagation medium. Figure 3 represents the relationship between the position of the GPR antennas and the depth of the target over the wave travel time.

Figure 4 illustrates the hyperbolic distribution of the relationship between spatial position, wave velocity and travel time, which, according to Annan (2003) [22], is given by Equation 2, Equation 3 e Equation 4.

$T=\frac{2 \sqrt{\mathrm{x}^{2}+\mathrm{d}^{2}}}{v}$

$T=\sqrt{\frac{4 \mathrm{x}^{2}}{\mathrm{v}^{2}}+T_{0}^{2}}$

$T_{0}=\frac{2 d}{v}$

where,

$T$ - round-trip wave time;

$\mathrm{x}$ - the projection of GPR position relative to target;

$d$ - reflection target depth;

$v$ - propagation velocity of the electromagnetic wave in the material; $T_{0}$ - travel time when GPR is directly over the target.

\subsection{Instrumentation}

A typical GPR system consists of the components and mode of operation [17], illustrated in Figure 5:

a) control unit, which is an electronic device consisting of a processor and memory for configuring storage, responsible for

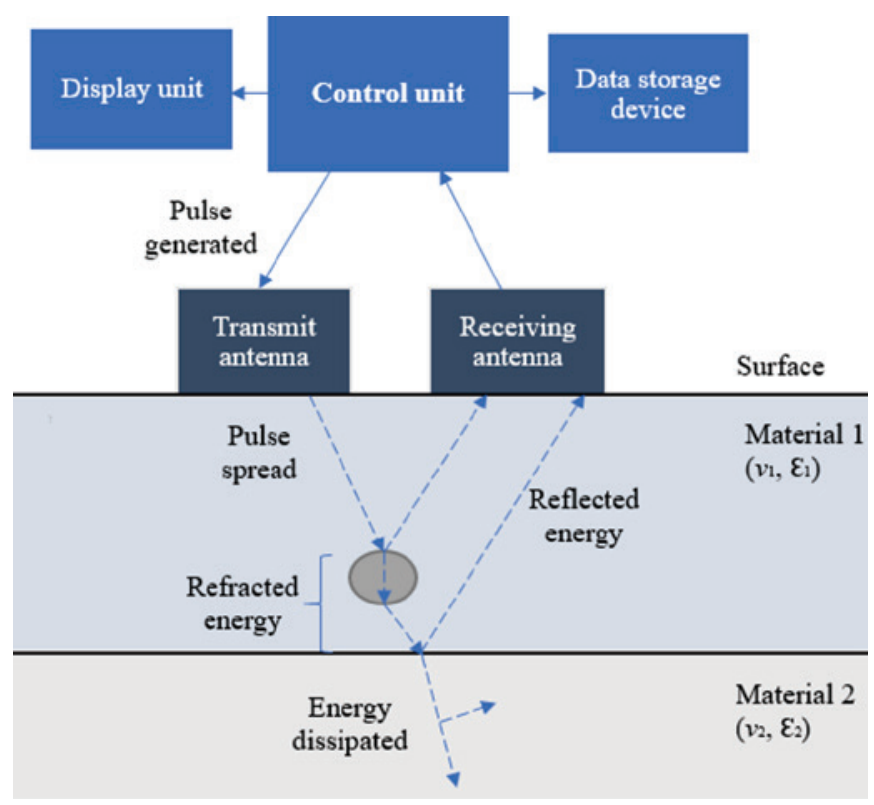

Figure 5

Components and mode of operation of a typical GPR system

Source: Adapted from Fernandes [17] 
Evaluation of the GPR $(1.2 \mathrm{GHz})$ technique in the characterization of masonry shells of the Theatro Municipal do Rio de Janeiro

Table 2

Depth of penetration, resolution and typical application of the usual centre frequency

\begin{tabular}{|c|c|c|c|c|}
\hline $\begin{array}{c}\text { Frequency (f) } \\
\text { MHz }\end{array}$ & $\begin{array}{c}\text { Wave length }(\lambda) \\
\mathrm{cm}\end{array}$ & $\begin{array}{c}\text { Depth of penetration } \\
\mathrm{m}\end{array}$ & $\begin{array}{c}\text { Vertical resolution } \\
\mathrm{m}\end{array}$ & Typical application \\
\hline 10 & 3000 & 50 & 7,500 & \multirow{3}{*}{$\begin{array}{l}\text { Geotechnics } \\
\text { and geology }\end{array}$} \\
\hline 25 & 1200 & 30 & 3,000 & \\
\hline 50 & 600 & 10 & 1,500 & \\
\hline 100 & 300 & 5 to 20 & 0.750 & $\begin{array}{l}\text { Geotechnical, } \\
\text { environmental } \\
\text { and mining }\end{array}$ \\
\hline 250 & 120 & 2 to 7 & 0.300 & $\begin{array}{l}\text { Geotechnical, } \\
\text { environmental } \\
\text { and structures }\end{array}$ \\
\hline 500 & 60 & 1 to 4 & 0.150 & \multirow{5}{*}{ Structures } \\
\hline 1000 & 30 & 0.5 to 1.5 & 0.075 & \\
\hline 1500 & 20 & 0.5 & 0.050 & \\
\hline 2000 & 15 & 0.4 & 0.035 & \\
\hline 2700 & 11 & $<0.4$ & 0.025 & \\
\hline
\end{tabular}

Source: Adapted from Annan and Fernandes [17,22]

generating thousands of electrical pulses per unit of time and sending them to the transmitting antenna, as well as receiving test data for processing;

b) radar antennas, which consist of transducers whose function in the transmitting antenna is to convert electrical current into electromagnetic pulses to be radiated in a controlled manner on the investigated surface, and the reverse occurs in the receiving antenna, which picks up the reflected electromagnetic pulses that are converted to an electric current;

c) display unit, consisting of a screen to display the graphical representation of time and distance data recorded in the test;

d) data storage device.

There are different modes of operation of GPR antennas, with the antennas being kept fixed or moving relative to the target. The mode adopted in the present research and the most common according to Annan (2003) [22], is called common-offset. The antennas move along the surface, but the distance between the transmitting and receiving antennas is constant and known, and the antennas are coupled to a protective plastic case equipped with an odometer, called a mobile unit.

The wave is transmitted, received and recorded each time the mo-

\section{Antenna position}

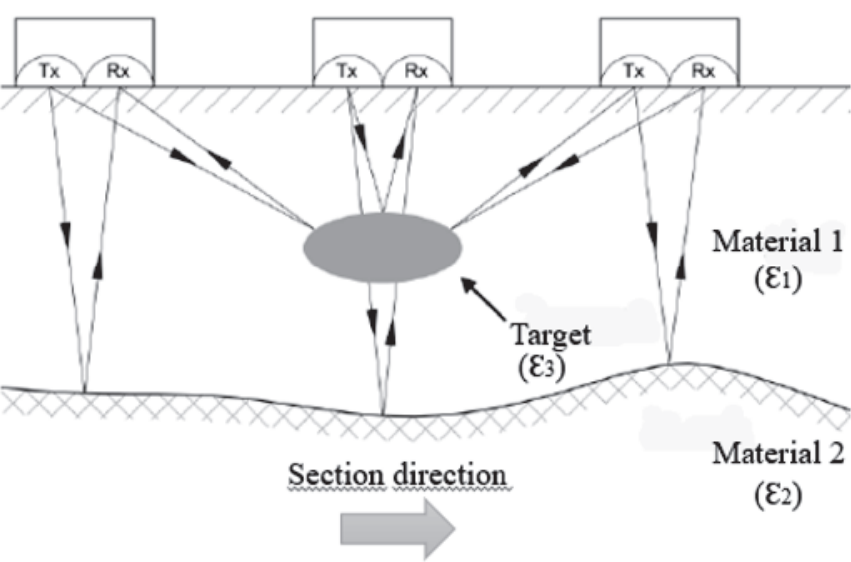

(a) bile antenna unit is moved, in a register called "trace". The spacing between traces should be adopted depending on the size of the target to be studied and the research objectives. A one-dimensional trace does not provide much information, but several traces displayed side by side forms a two-dimensional time-distance record of GPR or GPR cross-section or radargram showing the variation of reflections relative to the surface. Traces can also be arranged so that they represent three-dimensional blocks of the studied element [25].

\subsection{Resolution}

According to Daniels (2004) [25], the signal emitted by the transmitting antenna is a frequency spectrum, where the peak corresponds to the central frequency of the antenna (f). Such frequency may vary between $10 \mathrm{MHz}$ and $2700 \mathrm{MHz}$ and the choice of the appropriate working frequency depends on the application type, material, depth and possible dimensions of the targets to be studied. There are three key aspects to the decision making process: vertical resolution, which corresponds to the ability to distinguish two near-vertical points; spatial resolution, referring to the ability to distinguish two points at the same depth; and the

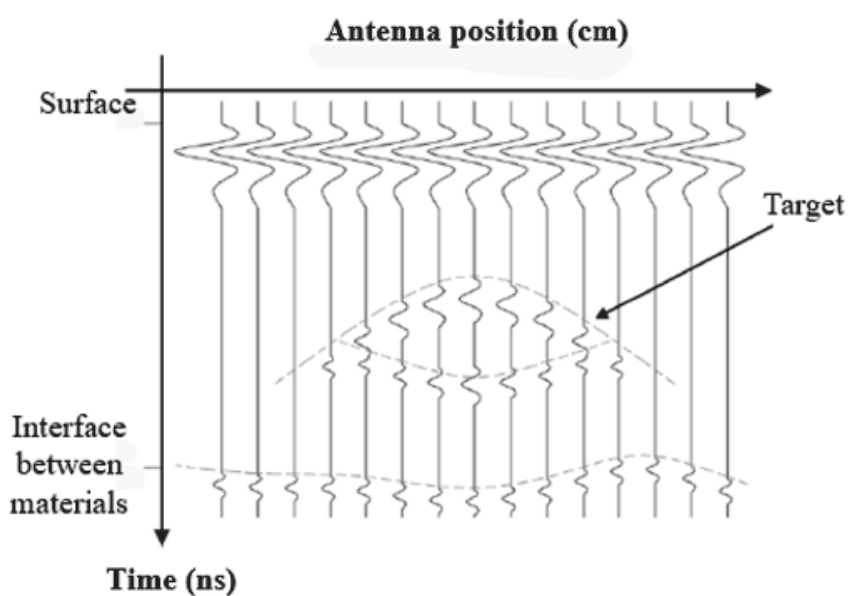

(b)

\section{Figure 6}

Wave reflection on a target (a) methodology and (b) resulting radargram

Source: Adapted from Fernandes [17] 


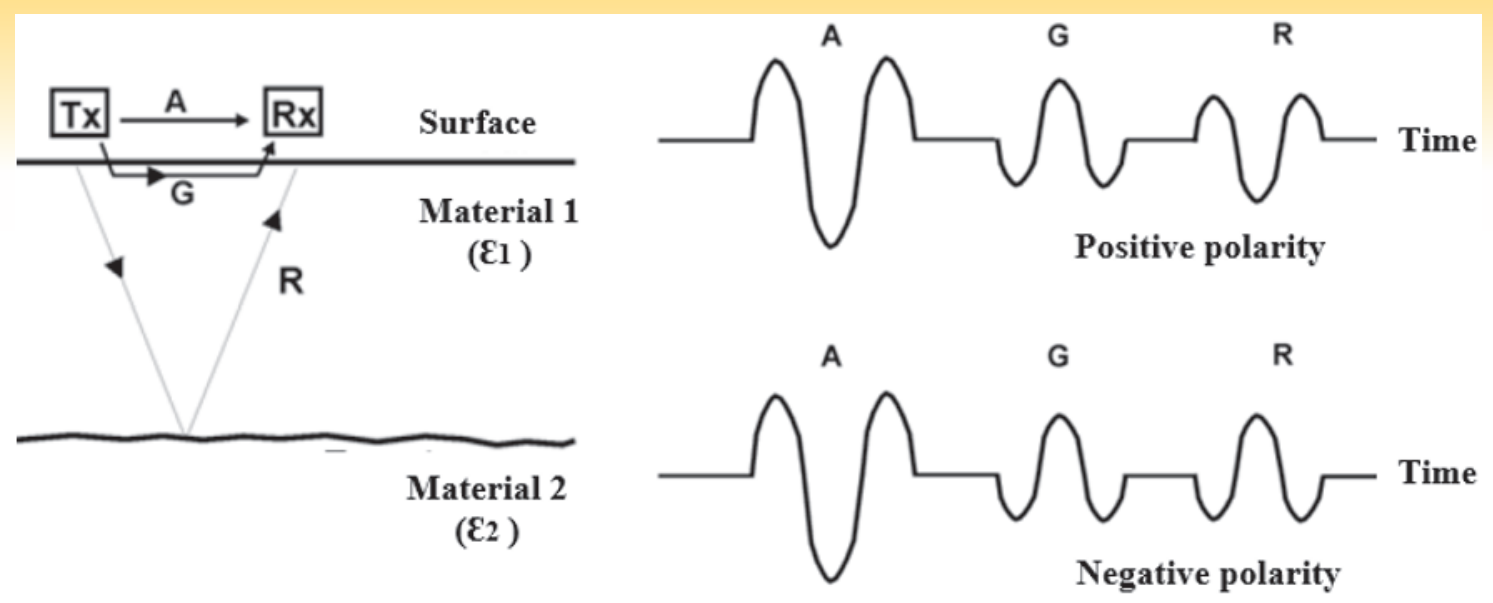

\section{Figure 7}

Wave pulse polarity

Source: Adapted from Annan [22]

minimum depth from which objects can be detected without obstructing the direct wave reflection signal [6]. Table 2 represents the penetration depth, expected resolution and typical applications for the centre frequency of radar antennas under favourable conditions. The lowest frequencies are applied in the geotechnical area $(\leq 250 \mathrm{MHz})$ and the highest frequencies in the area of structures (250 a $2700 \mathrm{MHz}$ ) [17,22].

Information resolution or accuracy of GPR survey results improves with increasing antenna frequency capacity, but is hampered by decreased signal propagation speed, decreased wavelength and decreased frequency peak due to the influence of the properties. dielectrics of solid materials. Generally, the resolution is enough if the dimensions of an object are larger than $1 / 4$ of the wavelength $(\lambda)$ of the incident radiation if no material non-linearity interferes with the wave propagation. In order to properly detect hidden elements, Annan (2009) [26] suggests that the horizontal $(\Delta x)$ and vertical $(\Delta \mathrm{t})$ distance between consecutive sampling points are defined by Equation 5 and Equation 6.

$\Delta_{x} \leq \frac{\mathbf{v}}{6 f_{c}}$

$\Delta_{t} \leq \frac{1}{6 f_{c}}$

where,

$\Delta \mathrm{x}$ - interval in space between consecutive sampling points;

$\Delta \mathrm{t}$ - time interval between consecutive sampling points;

$v$ - velocity of the electromagnetic wave in the medium;

$f_{C}-$ antenna centre frequency.

Radiation energy losses related to GPR equipment may affect the electromagnetic signal. According to Daniels (2004) [25] and Fernandes (2006) [17], these losses may occur due to:

a) inefficiency of the antennas to transmit and receive the entire signal;

b) instability that occurs in the coupling of antennas on uneven surfaces, which interferes with the radiation pattern of the antenna because it is a directional beam;

c) geometric scattering of the energy beam along with the depth;

d) dispersion of the electromagnetic signal from the incidence on the target itself;

e) signal attenuations due to the dielectric properties of the propagation means.

Prior to the test, it is necessary to limit the round-trip transit time of the signal $(\mathrm{T})$ according to the estimated depth of characteristics and targets present to avoid storing unnecessary data outside the expected time and speeding up field measurements.

\subsection{Data analysis and interpretation}

Turning GPR data into specific and applicable information can go two ways, according to Annan (2009) [26]. The first and most common one considers the measurements of a flat section or volume traces to indicate the spatial position of the target. The second determines quantitative variables from wave properties such as velocity, attenuation, impedance and converts them into specific quantities applicable to material properties, which is the tendency for GPR to evolve.

If the dielectric properties of materials have adequate contrast (Figure 6a), the GPR section can be considered a two-dimensional representation of the studied element and can be interpreted to define the internal characteristics of the element. Figure $6 \mathrm{~b}$ depicts a typical GPR section where the horizontal axis is the distance travelled along the surface of the element under study and the vertical axis is the wave round-trip time that can be converted to depth if the wave velocity or dielectric constant of the material is known. Figure $6 \mathrm{~b}$ represents the pattern of some of the features observed by Fernandes (2006) [17] in GPR sections of historic masonry. Isolated hyperbole reflections indicate the presence of individual and small embedded elements (targets) such as metal, wood or other material with dielectric property in contrast to masonry. The depth of the target can be determined by considering the vertex of the hyperbole. The presence of a significant area with a large number of reflections indicates the presence of deteriorated or heterogeneous material, such as cracks, voids, detachments. Long reflection signals parallel to the data acquisition surface correspond to the interface between different material layers, peelings or cracks in masonry.

As an estimate of the wave propagation velocity in the material, Annan (2003) [22] and Cassidy (2009) [23] suggest fitting a hyperbolic shape with known parameters that coincides with a reflection hyperbole in the GPR section, as represented in Figure 6b. From the combination of velocity (v) and propagation time (T0), it is also possible to estimate the depth (d) of the target.

GPR signal polarity may be useful in interpreting the data. Annan (2003) [22] suggests that a positive waveform has the shape of the letter "M" and the negative pulse has the shape of the letter "W". Figure 7 describes the basic elements of a GPR measurement as signals that travel directly through the air (direct wave A) and first reach the receiving antenna with positive polarity $(\mathrm{M})$. Then some 
Evaluation of the GPR $(1.2 \mathrm{GHz})$ technique in the characterization of masonry shells of the Theatro Municipal do Rio de Janeiro

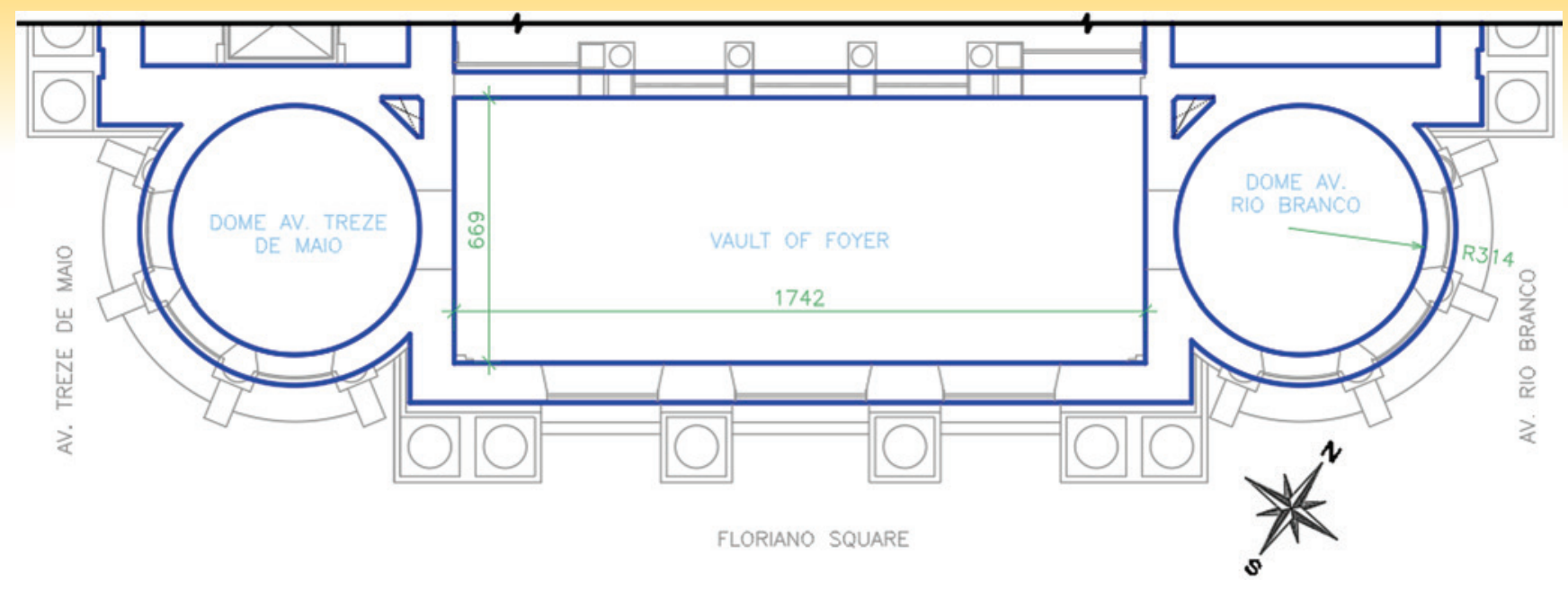

Figure 8

View of the intrados of the shells of the Theatro

signals travel directly through the material near the surface (direct wave $\mathrm{G}$ ), with negative polarity (W). Finally, signals that are reflected at the interface of a target within the element ( $R$ wave reflection) and take longer to reach the receiving antenna may have positive or negative polarity ( $\mathrm{M}$ or $\mathrm{W}$ ).

Reflection of a wave is caused by the change in electromagnetic impedance at the interface of materials. A target with an impedance greater than medium produces a positive pulse reflection, while a target with lower impedance produces a negative pulse reflection. Usually, rocks and voids represent high impedance materials and generate positive reflections in GPR. While metal is a very low impedance material and will always give rise to the negative reflection wave [22]. Properly displaying data is fundamental to analysing it. The choice of display parameters is an integral part of the interpretation of the GPR section. It is often impractical to display data as traces. The most common mode of a two-dimensional representation of data is a scanner image called a radargram. This consists of assigning colours (or varying the intensity of a single colour) to indicate the amplitude variation in the traces [22].

During the GPR test, data can be collected with unwanted incorporation of information that is not relevant to the research objectives, causing data overlapping effects that impair the desired target
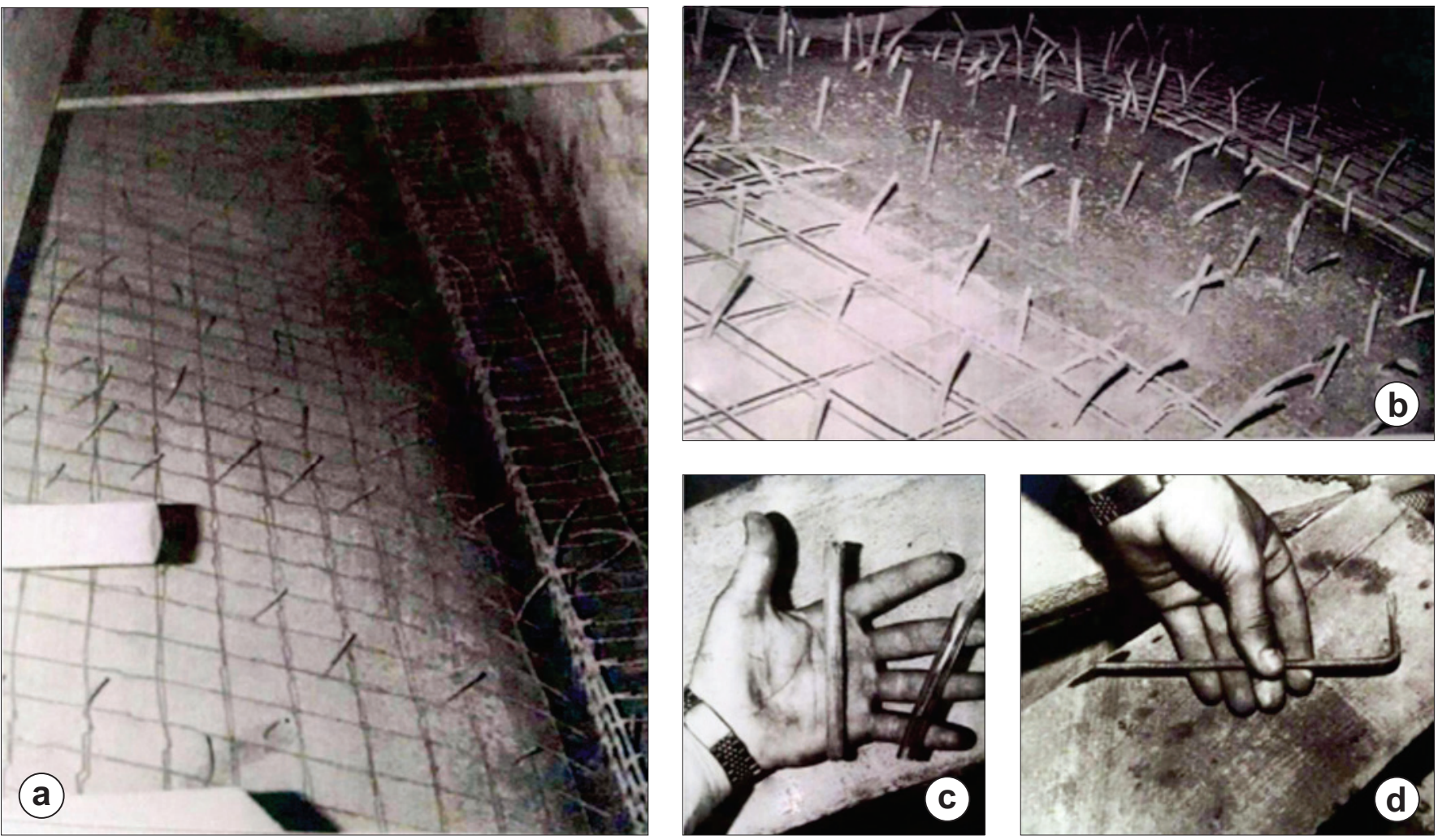

\section{Figure 9}

Photos of the reinforcement of the shells in the 1970s

Source: Schiros [27] 
signals. Such noises can come from sources such as vehicles, electrical cables, metals, telecommunications systems, mobile phones, pipelines, and natural electrical and magnetic phenomena [25]. The basic processing of the GPR section is the application of filters and gain, such as bandpass filters, DC removal, automatic gain control (AGC), among others available in the processing software. The relationship between signal and noise can be improved by applying filters that delimit the display of an appropriate frequency band for the antenna used. The gain application allows equalizing the amplitudes of each trace to compensate for signal attenuation due to depth propagation in solid materials [26].

\section{Data acquisition at the Theatro Municipal do Rio de Janeiro}

\subsection{Description of domes and vaults}

On the upper floor of the TMRJ, near the centre of the main façade, is the so-called noble area. As shown in Figure 8, there is the foyer, a welldecorated hall for the reception of the public and covered by a cradle vault with plan dimensions of the extrados of the $6.83 \mathrm{~m} \times 17.48 \mathrm{~m}$ and $2.60 \mathrm{~m}$ rise, built-in double-layer brick masonry laid with cement mortar and lime. The two side roundabouts have a spherical dome ceiling with a diameter of $6.28 \mathrm{~m}$ on the extrados, $2.75 \mathrm{~m}$ rise and were built in solid ceramic brick laid and covered with cement mortar and lime.

The domes and vault were built in 1907, supported on walls and pillars. The weather, festive events, vandalism, leaks on the roof, surrounding construction works, such as the nearby subway, among other occurrences, damaged the building. In 1976 they were reinforced with reinforced concrete. Schiro reports that the entire intervention was performed in three days, without stepping on the peels, without shoring so as not to damage the paintings on the soffit and consisted of the following steps [27]:

a) Step 1 - Construction of side beams and a superimposed shell in reinforced sprayed concrete to support part of the weight of the original shell, as shown in Figure 9a. In concreting, priority was given to the creation of arches over the largest transverse cracks (Figure 9b);

b) Step 2 - epoxy injection into the cracks to restore shell monolithism employing plastic traps as shown in Figure 9b;

c) Step 3 - anchoring of metal inserts immersed in epoxy-filled holes to promote adhesion between the original masonry shell and the new concrete shell as Figure $9 \mathrm{c}$ and Figure $9 \mathrm{~d}$.

The vault of the foyer and the dome of Av. Rio Branco are the objects of study. It is covered by a waterproofing blanket which, although deteriorated and detached from the shell in some parts, cannot be removed. performed on the blanket. The dome of Av. Treze de Maio was not studied due to its inaccessibility, so its characteristics are considered similar to the one on Av. Rio Branco.

\subsection{Methodology}

All data collection with GPR was performed in the extrados of the shells, after superficial cleaning and marking of the axes mesh with white chalk, avoiding stepping on the shells. The MALA GeoScience system consisting of $1.2 \mathrm{GHz}$ frequency antennas coupled to a wheeled mobile unit was used. Antenna displacement data were acquired through an odometer connected to the left rear wheel of the mobile unit.

Preliminary tests allowed to verify the pattern of visualization of metallic inserts, the adequate speed of movement and the coupling of the mobile unit of the antennas to the surface of the shells. The mobile unit odometer was also calibrated by comparing the length measurements a $5 \mathrm{~m}$ graduated measuring tape with $0.01 \mathrm{~m}$ accuracy. It was observed that the direct contact between the wheels of the mobile unit and the surface of the shells along the lifting path was impaired by the roughness of the projected concrete and mortar in the case of the dome, aggravated in by the waterproof blanket overlap. Thus, a $3 \mathrm{~mm}$ thick ethylene vinyl acetate (EVA) synthetic foam strip was used to facilitate the movement of the wheels of the antenna mobile unit over the shells as illustrate in Figure 10a and Figure 10b.
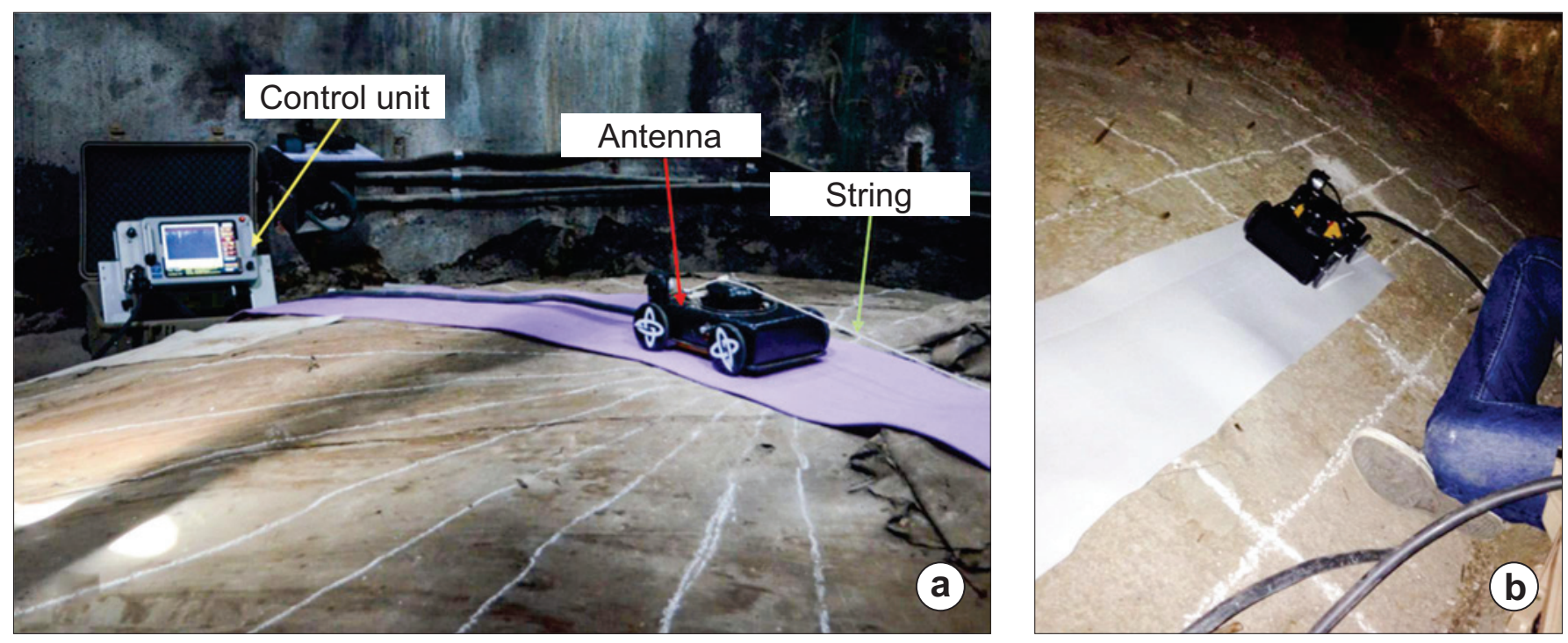

Figure 10

GPR test: (a) dome of Av. Rio Branco and (b) vault 


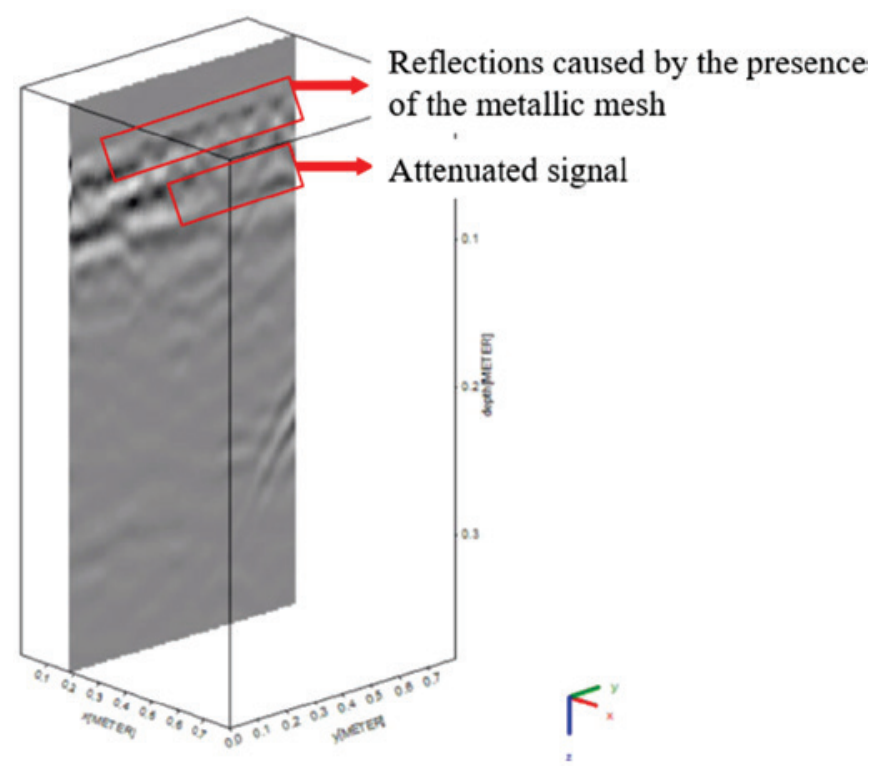

\section{Figure 11}

Three-dimensional investigation with an unsatisfactory result

For the regularity of data acquisition in the GPR sections, the moving speed of the mobile antenna unit was kept as constant as possible, which was manually conducted in the horizontal course. In the vertical direction, the acquisition unit was manually driven from the base of the shell to where it was possible to reach the hands. From there the vehicle was driven with the help of a string until it reached the vertex, following the marked axis lines while avoiding stepping on the dome and vault.

Data acquisition was performed in 24 sections of the Av. Rio Branco dome, 12 sections of the foyer vault and two sections in masonry sidewalls. 3D surveys were also performed in each of the studied elements, but the radargrams were not considered satisfactory for analysis due to the high reflection of the metal mesh and consequent signal attenuation in all areas below the mesh as shown in Figure 11.

The thicknesses obtained by the GPR test were used in a sub- sequent stage of research for the development of the numerical model for nonlinear analysis of the structure by the finite element method in order to investigate the vulnerability of structural elements, the causes of damage in the 1970s and the efficiency of previous intervention measures.

\subsection{Results}

Reflex2DQuick software, version 3.0, was used for processing two-dimensional radargrams and Reflex3DScan software for processing three-dimensional acquisitions. In the processing of twodimensional radargrams, the Dewow filter required for the MALA system data and gain function to compensate for signal attenuation along the depth [28] were applied. In three-dimensional acquisitions, the Dewow filter was also applied, as well as the Background Removal to eliminate direct wave interference.

The standard procedure for calibrating the electromagnetic wave propagation velocity in a material is by measuring the round-trip travel time in the section by positioning a sheet metal on the opposite surface of the element. However, due to difficulties in accessing the opposite surface of the dome and vault, such procedure was unworkable in the present study. These elements are composed of several materials, so the speed of masonry was adopted as the standard for the section since this is the predominant material in the constitution of the dome and vault. The wave velocity in the masonry was estimated at $0.15 \mathrm{~m} / \mathrm{ns}$, from the round-trip time recorded in the radargram of the sidewall of Av. Rio Branco dome (Figure 12a). This survey was done near a shaft, where the brick masonry was exposed and its thickness could be measured (Figure 12b). The adopted velocity is compatible with those determined by Fernandes (2006) [17] in the ceramic brick masonry of historical buildings.

The electromagnetic signal lost energy when it finds the bars of the wire mesh. Because of that, a significant dispersion occurs along the shell section, which impaired the determination of its total thickness and its constituent layers in most radargrams. Only in the sections where the reinforcement rate was lower or where the reinforcement was transverse to the antenna path the signal was propagated sufficiently along the section and it is possible to estimate the thickness of the dome and the vault. Therefore, it is available to estimate its layers, as well as to estimate its layers the size of the masonry units.
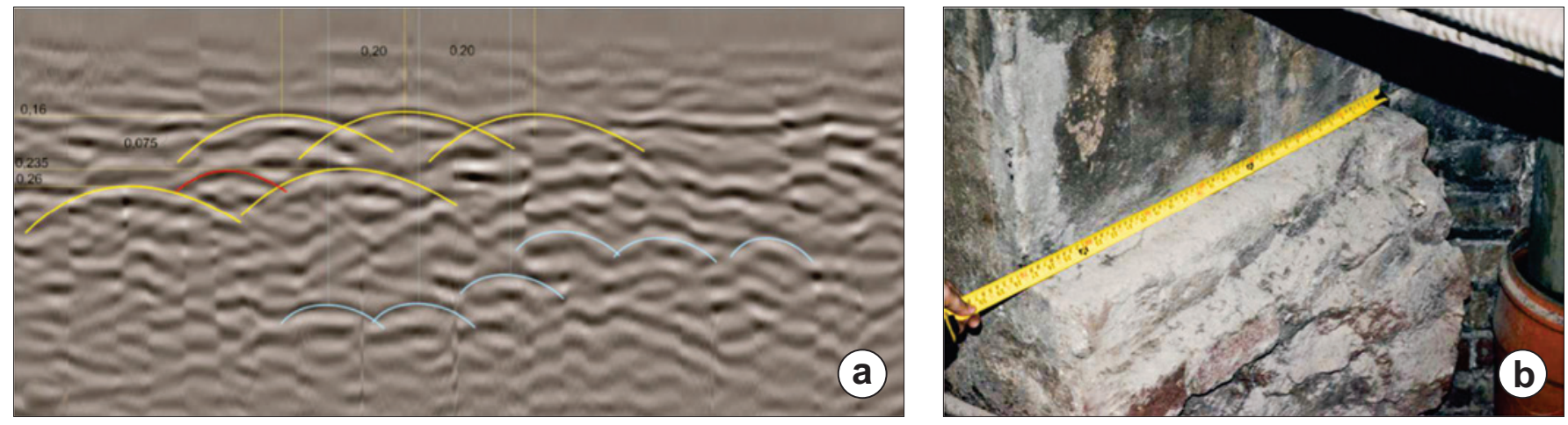

Figure 12

Dome sidewall (a) radargram (b) thickness determination 


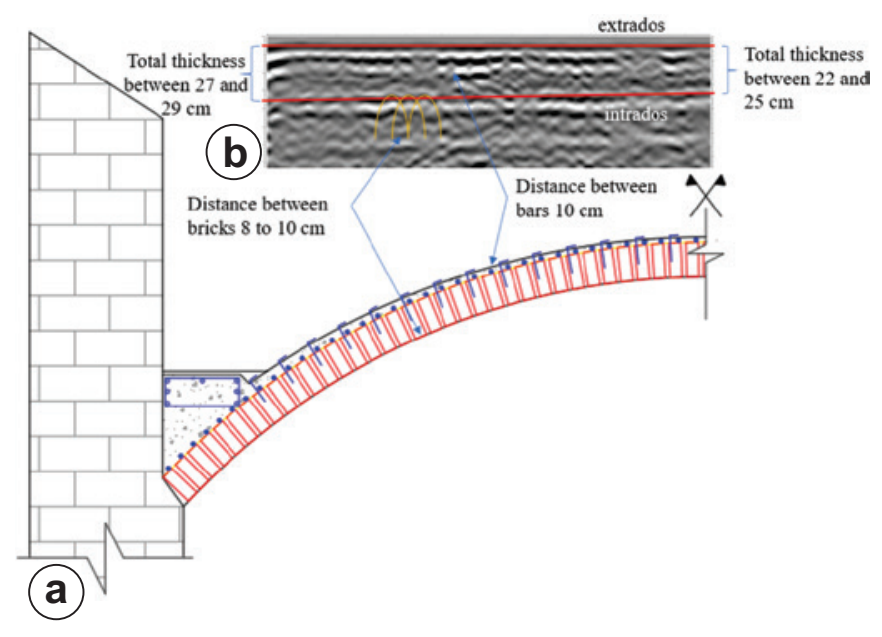

\section{Figure 13}

Cross section of Av. Rio Branco dome: (a) constructive detail; (b) radargram

Figure 13a represents the constructive characteristics of the Av. Rio Branco dome and Figure 13b shows a typical radargram. Figure $13 \mathrm{~b}$ indicates that the total shell thickness has a ranges from 22 and $25 \mathrm{~cm}$ at the vertex. The thickness tends to grow linearly towards the base, which appears to be about 2 to $5 \mathrm{~cm}$ larger. In several radargrams there was a pattern of small consecutive parables with spacing between 8 and $10 \mathrm{~cm}$ in the alignment of the soffit. It indicates that the vertical joint between bricks has dimensions compatibles with the correspondent joint found in thermograms and apparent bricks in the adjacent wall. The bars of the wire mesh has a spacing of $10 \mathrm{~cm}$, information confirmed in a pacometry test and described in the Schiro's report [27]. No intermediate layer was identified, which confirms the existence of only one bricklayer. Figure 14a represents the constructive characteristics of the foyer vault and Figure 14b shows a correspondent typical radargram. Figure $14 \mathrm{~b}$ indicates that the total shell thickness has a ranges from 20 and $23 \mathrm{~cm}$ at the vertex. The thickness tends to grow linearly towards the base, which appears to be about 5 to $8 \mathrm{~cm}$ larger. In some radargrams there was a pattern of small consecutive parables spaced in the alignment of the soffit. This spaces ranges from 16 to $20 \mathrm{~cm}$, indicating the bricks, whose dimensions are compatible with those found in thermograms. The bars of the wire mesh have spacing between 10 and $11 \mathrm{~cm}$, information confirmed in a pacometry test and described in the Schiro's report [27], as well as the presence of metal pins, with a typical spacing of $20 \mathrm{~cm}$. An intermediate layer was identified, confirming two bricklayers described by Schiros [27], possibly with a thickness between 10 and $12 \mathrm{~cm}$.

As they are elements composed of several materials, it was not possible to detect damage such as voids and cracks in the peel investigated by GPR with $1.2 \mathrm{GHz}$ antennas. For this purpose, it is suggested to use higher frequency antennas, whose resolution is most appropriate

From the shell thickness information evaluated by the GPR test and data obtained from other tests, the numerical model of the structure was elaborated in FX + for Diana software and nonlinear finite element analysis was performed in Diana version 10.2 software (Figura 15), whose results go beyond the objectives of the present work

\section{Conclusions}

The GPR technique with $1.2 \mathrm{GHz}$ frequency antenna was applied to the reinforced masonry dome and vault of the Theatro Municipal do Rio de Janeiro, aiming at estimating the total thickness of the elements and their layers, confirming constructive characteristics, measuring the brick dimensions with data from other tests and identify embedded elements. As these are structural elements composed of various materials, the speed of masonry was adopted as the standard for the section, as it is the predominant material in the constitution of the dome and vault. The wave velocity in the masonry was estimated at $0.15 \mathrm{~m} / \mathrm{ns}$, from the round-trip time recorded in the radar of the sidewall of the Av. Rio Branco dome, an element composed only of brick masonry, where it was possible to access to determine its thickness.

The dome had a thickness ranging between 22 and $29 \mathrm{~cm}$, consisting of a bricklayer. The vault had a thickness between 20 and $31 \mathrm{~cm}$, consisting of two layers of bricks. Such information served as a reference for the development of a numerical model used for nonlinear analysis of the structure by the finite element method, the results of which go beyond the objectives of the present work

It was not possible to detect damage such as voids and cracks. For this purpose, it is suggested to use antennas with larger frequency, whose resolution is more appropriate to the dimensions of the element.

The electromagnetic signal lost energy by focusing on the bars of the wire mesh, generating significant dispersion along the shell section, which impaired the determination of its total thickness and its constituent layers in most radargrams, especially in 3D surveys.

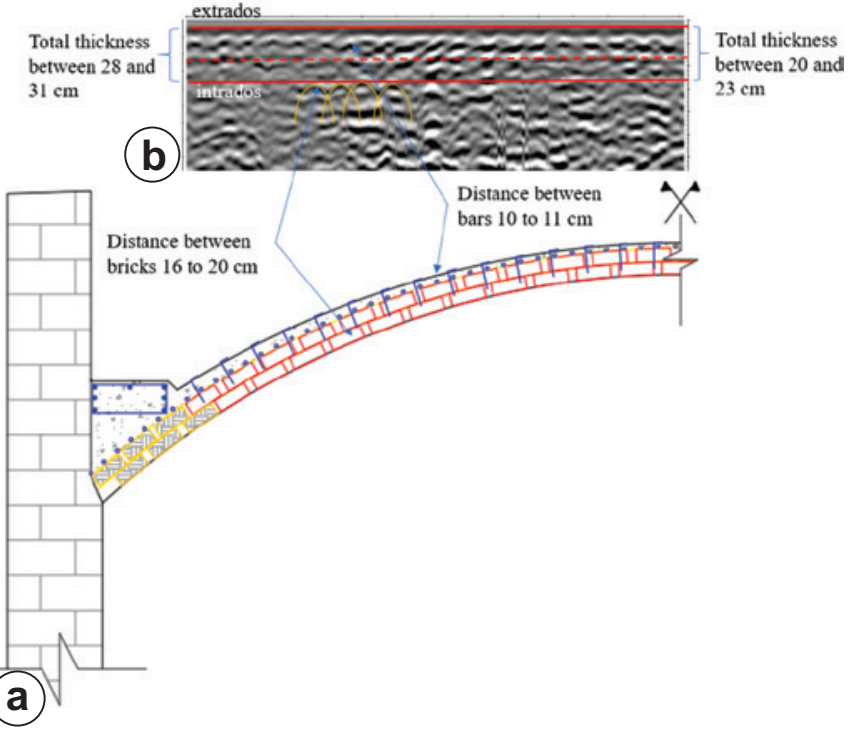

Figure 14

Vault cross section: (a) constructive detail; (b) radargram 


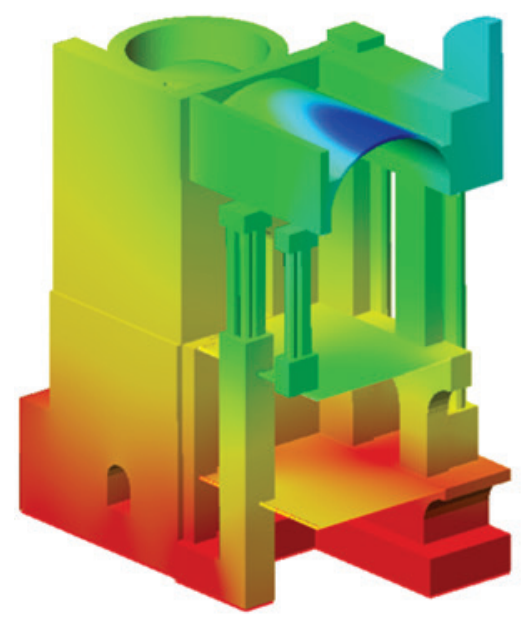

(a)
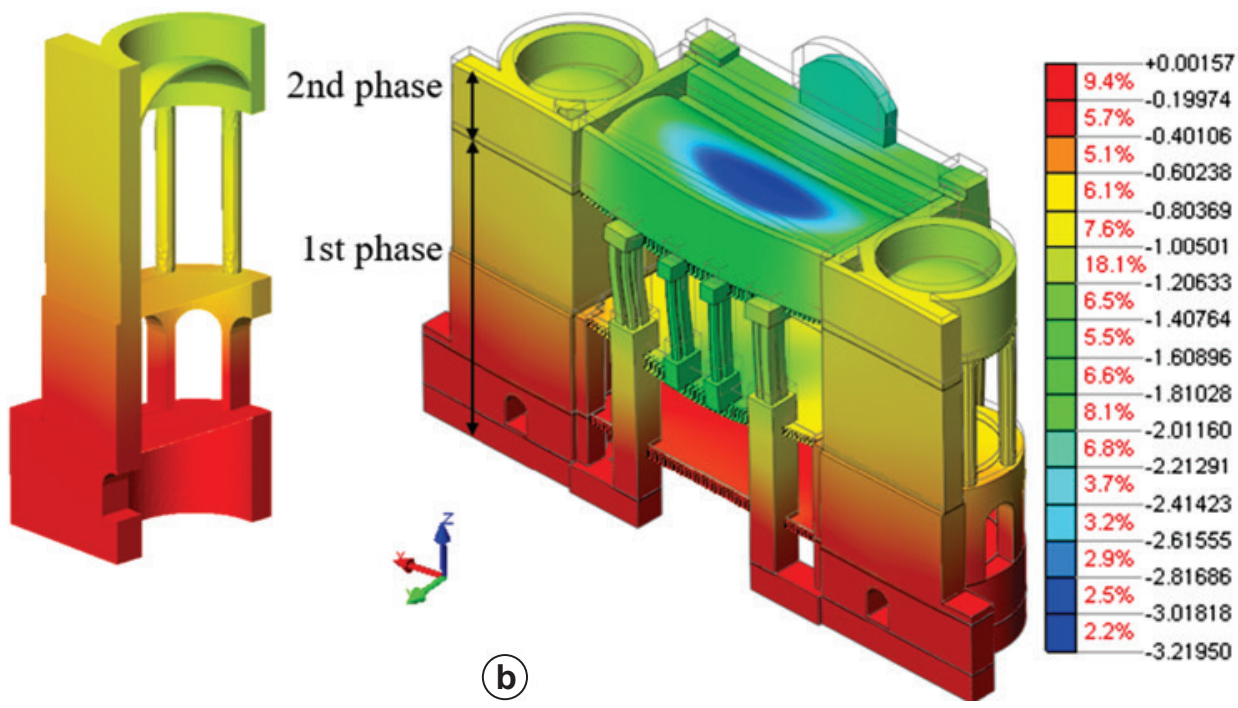

\section{Figure 15}

Numerical model: (a) detail of shell thickness; (b) vertical displacements ( $\mathrm{mm}$ ) of physical nonlinear analysis considering two constructive phases

Only in the sections in which the reinforcement was transverse to the antenna path the signal was propagated along the section, allowing to estimate the desired information.

The survey of GPR in old structures is still unusual, probably due to the difficulty in interpreting the images generated by the investigation of complex elements, which requires time and dedication to acquire knowledge and practice to properly use the technique. A prior study is necessary to know the construction process and any interventions suffered by the studied element, in order to have a prediction of the type of elements expected in the visualization of radargrams, as well as the verification of information collected by other complementary tests, documents or other means.

The present study seeks to contribute information to improve the GPR assay methodology and experimental data for structural preservation work in similar constructions, especially masonry shells.

\section{Acknowledgements}

The authors thank the Foundation of Theatro Municipal do Estado do Rio de Janeiro, in particular to the Engineering and Architecture Sector, for supporting the research. Also to the School of Engineering of the University of Minho. This study was financed in part by the Coordenação de Aperfeiçoamento de Pessoal do Ensino Superior - Brasil (Capes) "Taxas" and Faperj, process number E-26/201.812/2017.

\section{References}

[1] ICOMOS. "Recommendations for the analysis, conservation and structural restoration of architectural heritage". International Scientific Committee for Analysis and Restoration of Structures of Architectural Heritage. Paris, 2003. BALAYSSAC, J. P. et al. "Description of the general outlines of the French project SENSO - Quality assessment and limits of different NDT methods". Construction and Building Materials, v. 35, n. October 2012, p. 131-138.

[3] MILOVANOVIĆ, B.; BANJAD PEČUR, I. "Review of Active IR Thermography for Detection and Characterization of Defects in Reinforced Concrete". Journal of Imaging, v. 2, n. 2, p. 11, 2016.

[4] BENEDETTO, A.; BENEDETTO, F. "Application fieldspecific synthesizing of sensing technology - civil engineering application of ground-penetrating radar sensing technology". Reference Module in Material Science and Materials Engineering. Comprehensive Materials Processing, v. 13, p. 393-425, 2014.

[5] MANHÃES, P. M. B.; ARARUNA JÚNIOR, J. T.; PIRES, P. J. "Uso do GPR na identificação de elementos de fundação de edificações existentes", in: XVIII Congresso Brasileiro de Mecânica dos Solos e Eng. Geotécnica. Belo Horizonte, Brasil, 2016.

FERNANDES, F. M. C. P.; LOURENÇO, P. B.; CRUZ, P. J. S. "Possibilidades do radar de prospecção geotécnica em estruturas e aplicações em Portugal”. Engenium, 2010. p. 84-90.

[7] LAU, C.L.; SCULLION, T.; CHAN, P. "Modeling of GroundPenetrating Radar wave propagation in pavement systems", in: Transportation Research Record, Transportation Research Board. Texas, 1992. p. 99-107.

[8] LI, M.; ANDERSON, N.; SNEED, L.; TORGASHOV, E. "Condition assessment of concrete pavements using both ground penetrating radar and stress-wave based techniques", Journal of Applied Geophysics. 135 (2016) p. 297-308.

[9] BENEDETTO, A.; TOSTI, F.; CIAMPOLI, L. B.; D'AMICO, $F$. "An overview of ground-penetrating radar signal processing techniques for road inspections", Signal Processing. 132 (2017) p. 201-209. 
[10] DINH, K.; GUCUNSKI, N.; KIM, J.; DUONG, T. H. “Understanding depth-amplitude effects in assessment of GPR data from concrete bridge decks", NDT and E International. 83 (2016) p. 48-58.

[11] DINH, K.; GUCUNSKI, N.; DUONG, T. H. "Migrationbased automated rebar picking for condition assessment of concrete bridge decks with ground-penetrating radar", NDT and E International. 98 (2018) p. 45-54.

[12] ALANI, A. M.; ABOUTALEBI, M.; KILIC, G. "Applications of ground penetrating radar (GPR) in bridge deck monitoring and assessment", Journal of Applied Geophysics. 97 (2013) p. 45-54.

[13] DINH, K.; GUCUNSKI, N.; ZAYED, T. "Automated visualization of concrete bridge deck condition from GPR data", NDT and E International. 102 (2019) p. 120-128.

[14] BENEDETTO, A. "A three-dimensional approach for tracking cracks in bridges using GPR", Journal Applied Geophysics. 97 (2013) p. 37-44.

[15] ÁLVAREZ DE LARA, R. R. "Structural analysis of the church of the Monastery of São Miguel de Refojos”. 2016. $147 \mathrm{f}$. Dissertation (Advanced Masters in Structural Analysis of Monuments and Historical Constructions). University of Minho. Guimarães, 2016.

[16] BINDA, L.; SAISI, A.; TIRABOSCHI, C. "Investigation procedures for the diagnosis of historic masonries". Construction and Building Materials, v. 14, n. 4, p. 199-233, 2000.

[17] FERNANDES, F. M. C. P. "Evaluation of two novel NDT techniques - microdrilling of clay bricks and ground-penetrating radar in masonry". Tese (doutorado). University of Minho. Guimarães, 2006.

[18] SANTOS ASSUNÇAO, S.; PEREZ GRACIA, V.; CASELLES, O.; CLAPES, J.; SALINAS, V. "Assessment of complex masonry structures with GPR compared to other non-destructive testing studies". Remote Sensing, n. 6, p. 8220-8237, 2014.

[19] ZHAO, W.; FORTE, E.; FONTANA, F.; PIPAN, M.; TIAN G. "GPR imaging and characterization of ancient Roman ruins in the Aquileia Archaeological Park, NE Italy", Measurement. 113 (2018) p. 161-171.

[20] IPHAN, "Lista dos bens tombados e processos em andamento (1938 - 2018)", (2018). http://portal.iphan.gov. br/uploads/ckfinder/arquivos/Lista_bens_tombados_ processos_andamento_2018 (accessed on December 10, 2018).

[21] CINTRA, D. C. B.; ROEHL, D. M.; SÁNCHEZ FILHO, E. S.; SANTOS, M. F. S. F.; FILIZOLA, G.; ASSUMPÇÃO, M. S. "Structural Intervention Case in the Theatro Municipal do Rio de Janeiro", in: 3rd International Conference on Protection of Historical Constructions. Lisbon, Portugal, 2017.

[22] ANNAN, A. P. "Ground-penetrating radar - principles, procedures \& applications". Mississauga, Canada: Sensors and Software Inc., 2003.

[23] CASSIDY, N. J. "Electrical and magnetic properties of rocks, soils and fluids". In: Ground penetrating radar theory and applications. Oxford, United Kingdom: Elsevier Science, 2009. p. 46.

[24] ALSHARAHI, G.; DRIOUACH A.; FAIZE, A. "Performance of GPR influenced by electrical conductivity and dielectric constant". Procedia Technology, v. 22, p. 570-575, 2016.

[25] DANIELS, D. J. "Ground penetrating radar". 2. ed. London: The Institution of Electrical Engineers, 2004.

[26] ANNAN, A. P. Electromagnetic principles of ground-penetrating radar. In: Ground penetrating radar theory and applications. Oxford, United Kingdom: Elsevier Science, 2009. p. 4-40.

[27] SCHIROS, L. M. "Recuperação estrutural das cúpulas do foyer do Theatro Municipal do Rio de Janeiro". Colóquio sobre Patologia do Concreto e Recuperação Estrutural - Instituto Brasileiro do Concreto (IBRACON), p. 188-204, 1978.

[28] SANDMEIER, G. R. Reflex2D Quick, version 3.0. Karlsruhe, Germany, 2017.

[29] FUNDAÇÃO DO THEATRO MUNICIPAL DO RIO DE JANEIRO. "Evolução arquitetônica do Theatro Municipal". Drawings. Rio de Janeiro, 2009. 